\title{
ArtiFacts: The Case of Jules Pedoux
}

\author{
Alan J. Hawk BA
}

II n 1893, Jules Pedoux of Paris, France, contracted a tuberculosis infection, which included an abscess in his shoulder. Pedoux's physician recommended disarticulating the shoulder, but he refused. Because of this, his surgeon, Jules Emile Pean, commissioned J. Porter

\footnotetext{
A Note from the Editor-in-Chief:

We are pleased to present the next installment of ArtiFacts. In each column, the Collections Manager of the Historical Collections Division of the National Museum of Health and Medicine (NMHM) will present a photograph of a visually or historically interesting artifact from the museum's collection, and provide the story behind the picture. Now a National Historic Landmark, the NMHM was originally developed from the Army Medical Museum, which was established during the Civil War to collect "specimens of morbid anatomy together with projectiles and foreign bodies removed." Its mission today is to inspire interest in, and promote the understanding of, medicine to the public.

The author certifies that he, or any member of his immediate family, has no funding or commercial associations (eg, consultancies, stock ownership, equity interest, patent/ licensing arrangements, etc.) that might pose
}

Michaels, a dentist, to craft a shoulder prosthesis [1].

Mr. Michaels fashioned the prosthesis (Fig. 1) from materials commonly used to make dentures at that time: Vulcanite and platinum. He selected these materials because they did not oxidize and were unlikely to

a conflict of interest in connection with the submitted article.

All ICMJE Conflict of Interest Forms for authors and Clinical Orthopaedics and Related Research ${ }^{\mathrm{B}}$ editors and board members are on file with the publication and can be viewed on request.

The opinions expressed are those of the writers, and do not reflect the opinion or policy of $C O R R^{\circledR}$ or The Association of Bone and Joint Surgeons ${ }^{\circledR}$.

The opinions or assertions herein are those of the author and do not represent the views of the Department of the Army, Navy or Air Force or of the Department of Defense.
A. J. Hawk BA ( $\square)$
National Museum of Health and
Medicine, Defense Health Agency, 2460
Linden Lane, Silver Spring, MD 20910 ,
USA
e-mail: alan.j.hawk.civ@mail.mil

inflame the tissue. The shoulder joint prosthesis he designed took the form of a universal joint, which allowed Pedoux's arm full ROM. The holes on the sides of the shaft were intended for the attachment of muscle. The shaft was equipped with pivot joint, allowing medial rotation of the arm. It was attached to the humerus with screws and the prosthesis was attached to the scapula with platinum wire [2].

On March 11, 1893, Pean removed the synovium and the humeral head, and implanted the prosthesis, becoming the first known surgeon to attempt a shoulder arthroplasty. The patient was ambulatory 12 days later, and discharged from the hospital 20 days after the procedure [1]. Pedoux was able to get work as a waiter, as he could open and pour wine, and hand out glasses without drawing attention to himself. However, several fistulas developed along the line of incision, resulting in removal of the prosthesis in 1895. Although unsuccessful as a prosthesis, it proved that the human body could tolerate an artificial implant, which paved the way for the development of joint arthroplasty in the mid-20 $0^{\text {th }}$ century [2]. 


\section{ArtiFacts}

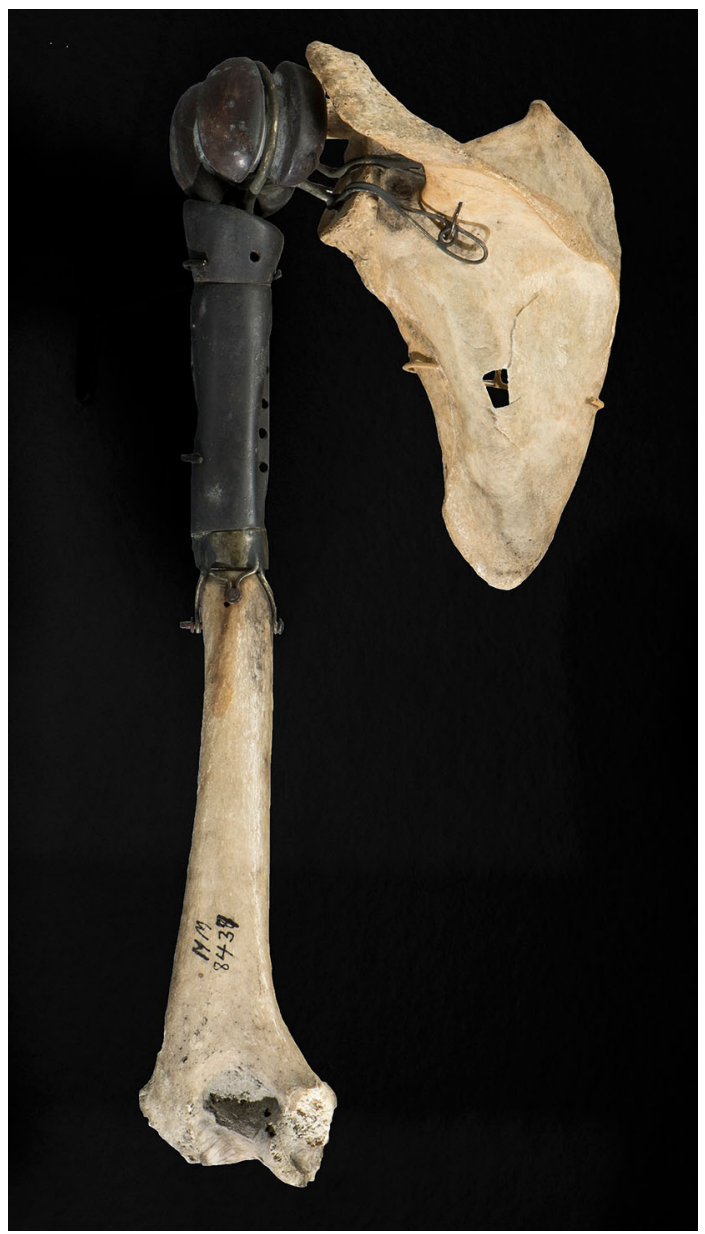

\section{References}

1. Alta T. Reverse Shoulder Arthroplasty. Does It Work? Kinematic Analyses, Clinical Evaluation, and New Developments. Rotterdam, The Netherlands; Rotterdam, The Netherlands: 2014.

2. Bogue EA. A prosthetic appliance devised and constructed by Dr. J. Porter Michaels of Paris, to replace a necrosed shoulder joint, removed by Dr. Pean. Am J Surg. 1916;30:266267.

Fig. 1 In 1893, the surgeon Jules Emile Pean commissioned J. Porter Michaels, a dentist, to craft a shoulder prosthesis for his patient, Jules Pedoux. Mr. Michaels crafted the prosthesis from materials he commonly used to make dentures - vulcanite and platinum. (This image has been manipulated by using dodging and burning techniques. It has been cropped to emphasize the subject. National Museum of Health and Medicine photo illustration by Matthew Breitbart/Released). 